\title{
AN OVERVIEW ON THE TREATMENT OF WASTE WATER USING RENEWABLE ENERGY
}

\author{
Debarghya Halder ${ }^{1}$, Subhajit Mondal ${ }^{2}$, Anupam Mukherjee ${ }^{3}$, Avijit Ghosh ${ }^{4}$ \\ ${ }^{1,3}$ Student, Department of Chemical Engineering, Haldia Institute of Technology, West Bengal, India \\ ${ }^{2}$ Student, Department of Electrical Engineering, Haldia Institute of Technology, West Bengal, India \\ ${ }^{4}$ Assistant Professor, Department of Chemical Engineering, Heritage Institute of Technology, Kolkata, \\ West Bengal, India, Corresponding Author: Dr. Avijit Ghosh, Email:avijit.ghosh@heritageit.edu
}

\begin{abstract}
The livelihood of the living species is impossible without water. Human beings need water in their day to day life. Water forms one of the vast usable natural resource. $3 / 4^{\text {th }}$ of the earth's area is occupied by water resources. But Out of these only $3 \%$ of the water is available fresh while rest $97 \%$ is in saline form. So as a whole there is scarcity of freshwater on this earth. And focusing upon the fact we can infer that there is a need of water for livelihood purposes. For this there are two ways of availing fresh water, one is by getting a fresh water resource while the other is purifying the water available and then using it. The former process has its limitation as because of natural scarcity while the later forms an important factor to work upon. Since ancient era efforts were there to avail pure drinking water Man has used every possible means to store the water for necessary purposes since ancient times but the population growth is uncontrollable. Due to this in today's modern world more effective processes are to be applied for survival of mankind. We know there is a scarcity of non-renewable energy. This review mainly focuses upon the processes of purification of water by means of renewable energy resources. This processes were used earlier and would be used in future also for the purpose of purifying water. The main objectives in this paper highlights are the renewable energy harvesting and treatment of wastewater. It summarizes the available techniques of treating water in large scales and small scale purposes, which may be cost effective according to community standards and the amendments which the technique has undergone proving more effective for purification of water. Some of the processes of purification which it focuses upon are desalination of water using reverse osmosis, water made to undergo photo-catalysis, electro-dialysis of water and UV filtration. These technologies are successfully used to completely remove component thus proving their effectiveness. With application of renewable energy they undergo performance analysis. Using Photovoltaic systems $(P V)$,conversion of wind energy to electrical energy for powering up the water purification treatment process.
\end{abstract}

Keywords: Ultraviolet (UV) Filtration; Electro Dialysis; Reverse Osmosis; Desalination Photo Catalysis.

\section{INTRODUCTION}

Environment grows upon some basic building blocks of matter. Water is the most important constituent which acts as a building block. No other matter has such vast usability as water has. It is an indispensable part of our life. Most of the earth is occupied by the water bodies. But not all of these water is in pure form and a very small percentage (only 3\%) is available fresh. Rest of the water present can't be used directly as because it may be in solid state in form of glaciers, as salty water in water bodies, and a part of it is available in acquifers which forms the ground water table. But focusing on a direct view the resources available are finite and continuous supply is something imaginary. Water changes its form under a cycle known as hydrological cycle. But considering the geographic factors not everywhere water comes down to earth equally i.e. rainfall differences are there. So for people surviving in low rainfall areas water is much valuable to them as livelihood is not possible without the presence of water. In today's world water scarcity is an outcome of the over-roaching population striving on this earth. World has developed but everything has a disadvantage of its own as well. So water scarcity is a major problem to deal with. The water sources can be predicted to be somewhat non-renewable in coming future generations. Industrialization and urbanization has played a huge role in creating job for normal people. But every Industrial processes require water indirectly or directly. So a huge amount of water gets consumed by these industries. Water plays a major role in controlling climate as well. So affecting water resources means outcomes of climatic changes. So now concentrating upon the fact that no other alternatives are there which would replace water, necessary steps should be taken to purify the available non-usable water. Waste water treatment has turned out to be a prime necessity today. But before going into details how wastewater treatment is done and the advantages and disadvantages of different techniques used let us highlight upon the fact that how water changes its state to form a cycle and gets circulated in nature. 


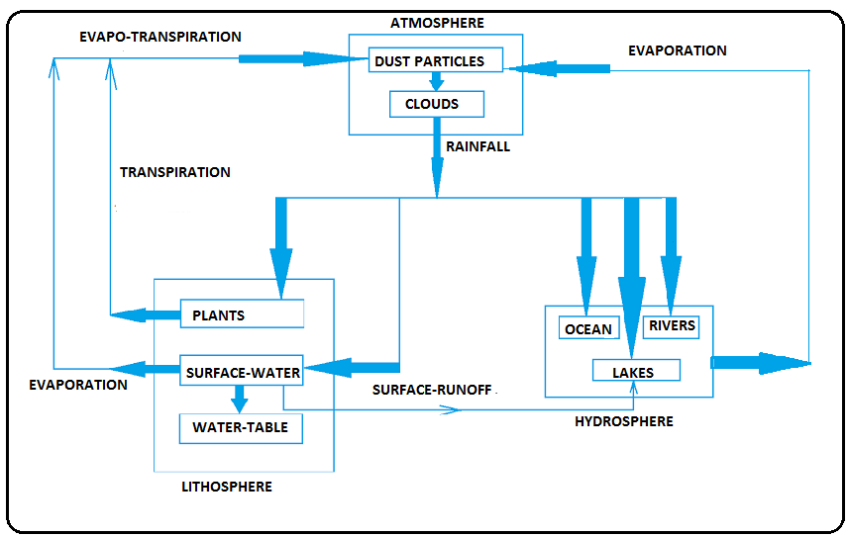

Fig-1: Hydrological Cycle

\section{RENEWABLE WATER SUPPLY RESOURCES}

The water gets circulated in this earth. In other words we can say that the presence of water calculated per volume of is constant in our planet [1]. It just changes its form and gets circulated following a cycle. Therefore accordingly we can say that water is a renewable source of supply. But contrary to the fact there is different level of precipitations are obtained in different areas which have different climatic conditions as per geographical features. The water resources found in different areas may or may not be accessible. For the purpose of supply of water applications of techniques are required. Utilizable water resources in the country of India occupies a volume of about $1086 \mathrm{~km}^{3}$ [2]. We see that the average sources of water are of two types (1.Water collected from a source on earth 2.Accesing water which is already stored). There are various technologies by which the water supply is done. Depending upon the community standards technologies are applied. In rural areas manual labor and low budget pumps are used for water supply. The water is stored at level below the surface (water table). With the help of bio-fuel pump, diesel pump, hand pumps, tubewells etc. water is pumped easily in rural areas [3]. But in urban areas water is collected from a water body and is stored in tanks which undergo purification processes discussed later which is supplied to different houses via pipelines.

\section{WATER SUPPLY TECHNOLOGY}

There are many water sources available (like acquifer, water body etc.) accessed the water should be available for supply to the common public. By any means it should reach each and every one striving in a community. According to community standards technology of water supply is much better and efficient. But even though with a loose or strong economic background, the development of different techniques has done to support water supply in every community. Let us a now highlight the technologies used in rural and urban communities.

* Rural:Even though India has extended its development program in many parts of India but taking it as an average many of the areas are yet to undergo necessary developments. Manual labor forms the base of everything in rural India. The main criterion for a rural water supply technology is the mechanism should run at low cost, low maintanence cost. Open wells and Hand pumps are the most available water supply options in rural areas. There are many types of mechanisms by which water can be taken out from the wells (like pulley rope and bucket)[4]. Hand pumps can be easily installed and maintained in rural areas as public water supply source. There many hand pump models used in rural areas (TARA, JIBON, INDIAN MARK I, INDIAN MARK II etc.)[5]. Other water supply systems includes gravity flow water supply where natural water storage is at higher level and small motorized pump systems.

* Urban: For urban water supply generally pipelines are made to house. As water resources are finite generally a located water body is connected through a pipeline to a storage tank which is able to supply water throughout a big area. The water pumped out from the water body is stored. Since this water is not in a purified state so it needs to undergo treatment so as to be used. So different techniques are available by which the water is made to undergo purification treatment (like active sludge treatment in case of waste water, conventional water treatment etc.).

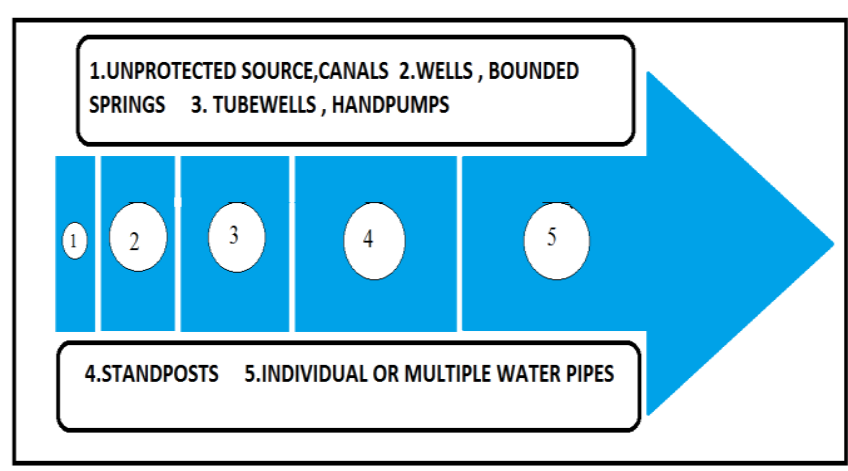

Fig-2: Development in water supply

\section{METHODS OF TREATING WASTE-WATER}

Wastewater needs to be treated for the purpose of use in daily livelihood. Every human-being needs water to survive. And good quality of water is a necessary requirement everywhere. Depending on how much a community can afford different water treatment methods are applied. There are three methods of treatment of waste-water:

- Traditional Ground-water Treatment

- Conventional Surface-water Treatment

- Municipal Waste-water Treatment

\subsection{Traditional Ground-Water Treatment}

The ground water is generally stored in water-table. Rainfall is the form of precipitation by which the water which gets evaporated due to evapotranspiration comes down to earth. This water gets stored underground in acquifers. Due to the soil quality of a particular area the minerals which gets dissolved is of varying amount like iron, manganese, salt, fluoride which gives the water a different odor and smell. To get rid of these, treatment of water is done as the undesirable contents present are waste and are of no use. There are two 
types of acquifer, confined and unconfined. The unconfined acquifer has an outlet which connects it to the ground may be in a form of stream. This open outlet makes the water prone to mix with the different types of fertilizers form the agricultural fields, animals drink water from those outlets thus it may initiate microorganisms and pathogenic activity making water unhealthy for drinking purposes and other uses. The impurities gets dissolved in water. For Example, aeration technique is applicable where small traces of manganese is present and using sand filter they form black sediments which can be removed. Rest of the chemicals like fluoride and others which can't be removed is made to undergo chemical treatments where complex sectors are divided for sedimentation, chlorination etc. [6]. But since availability of such chemicals are absent in rural areas so this techniques may be applied later on for development.

\subsection{Conventional Surface Water Treatment}

The most commonly used method of surface water treatment is the conventional method. This method is generally used in developed countries and in urban regions. The water which is required for multiple purposes needs to undergo adequate treatment so as to be suitable. Since most of the diseases are water-borne so compromising with the quality of water would be a big mistake. The unit operation treatment process which should be done on water are rapid mixing, flocculation, sedimentation, filtration, disinfection [7]. In conventional water treatment process the water is first made to go through a screening process in which the heavier particles are removed. Pre-sedimentation is done and then the water is made to go into the coagulation tank. The particles which remain suspended gets coagulated with the coagulating agents and form heavy masses which can be removed by sedimentation and filtration. Flocculation is mainly a process where the water is stirred gently so that big masses are formed and under the force of gravity they tend to settle down later removed by the process of sedimentation. The water is finally disinfected by chlorination or any other processes. The above processes of coagulation, flocculation and sedimentation can be designed in single tank and would be known as the clarification tank while the design of coagulation and flocculation can be designed in a single tank and the sedimentation is designed in other tank.

\subsection{Municipal Waste-Water Treatment}

The treatment of municipal waste-water is done by the most common process known as the activated sludge process. In this process, BOD (Biochemical Oxygen Demand) removal is used. With the help process of suspended growth treatment, a biological process the removal of BOD is done. It is an aerobic process in which the aeration is done of waste-water with the help of oxygen. The flocks which get created due to bacterial growth is removed with the help of secondary clarifier. By agitating the liquid with the help of aeration devices the oxygen is supplied to the matter for enhancing more bacterial growth under good maintained conditions. The waste-water is retained for a specific time measured, like 3 to 8 hours, if the BOD demand is more time required is more as well. The separations of microorganisms are done later on with the help of sedimentation and there remains the clarified liquid which is known as the secondary effluent. The sludge generated, a portion of it is recycled back into the aeration basin, which helps to maintain a high mixed-liquor suspended solid (MLSS) level. The remains are now removed and sent to sludge processing again so as to maintain a constant micro-organism level in the tank [8].

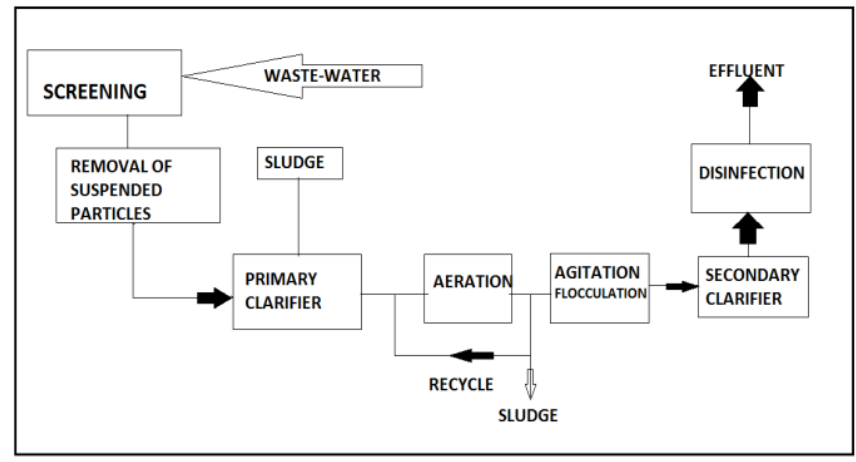

Fig-3: Active sludge treatment

The facultative ponds form another means of decomposing the raw-waste paper with the help of micro-organisms. The conditions prevailing for the decomposition should be anaerobic but near the surface mainly aerobic decomposition takes place, while in the lower parts anaerobic decomposition takes place while at lower layers anaerobic decomposition takes place. In aerobic zone in presence of oxygen the aerobic bacteria decompose the organic wastes to release $\mathrm{CO}_{2}$ while in anaerobic zone methanoic activity takes place.

\section{DIFFERENT ENERGY TECNOLOGIES BY WHICH WATER CAN BE TREATED}

\subsection{Electro-Dialysis}

Electro-dialysis is a process mainly used for desalination of brackish water. Moreover, the technology has found its application in the treatment of waste-water. The waste materials (like dissolved salts, metal ions etc.) can be removed from to be treated water using this technology of electro-dialysis. Under the influence of the electric-field the ions can be transported through selective-membranes. By placing these membranes alternatively a conventional stack is formed to form many compartments between the two elctrodes present at the two ends. By applying a potential difference between the two electrodes the cations are made to go toward the cathode and the anions are made to go towards the anode. The ion exchange membranes work in a way such that the cation-exchange membranes retain the anions allowing the cations while the anion-exchange membranes allow the anions retaining the cations. While a check on the compartment shows that alternate compartments gets more concentrated while the rest remains in the diluted state. The number of ions removed is directly proportional to the electrical power consumed $[9,10]$. The electric power requirement source should be something 
which is renewable. Since there are areas where electricity is not available an alternate source which should be able to convert energy consumed to electrical energy for power supply should be chosen. A PV (photo-voltaic) system consists of three parts solar arrays, balance of the system and the electrical load. Now for the purpose of providing powers in the non-solar hours a mechanism should be chosen. Electrical rechargeable batteries are more preferable. The arrays absorb sunlight in the outdoor environment in form of solar energy which gets converted into electrical power and the direct current is converted into alternating current with the help of inverters. Arranging solar arrays in parallel or series maximum output is gained as per power requirement $[\mathbf{1 1}, \mathbf{1 2}]$.

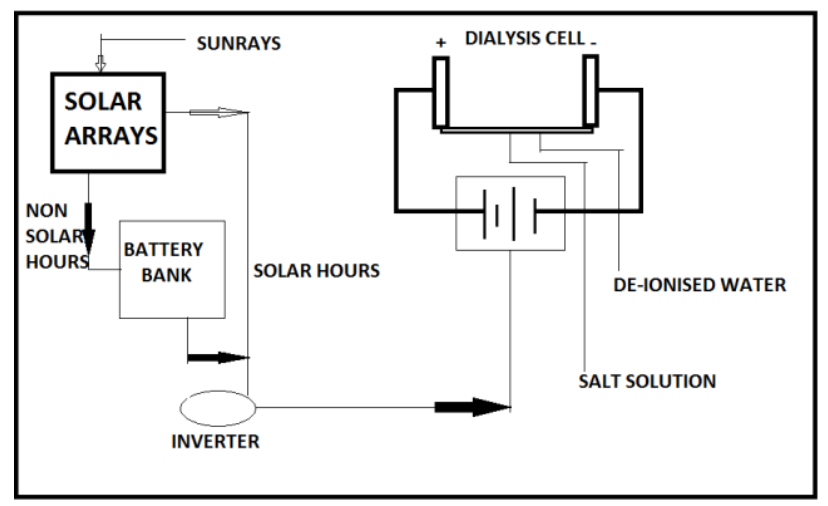

Fig-4: Electro-Dialysis with Solar power

The ED systems are mainly found economical for the brackish water desalination. However there are advantages and disadvantages of this process. The process doesn't require any chemical aid for its completion, no pre-treatment of water, high recovery rates are obtained and membrane lifetime is more due to system stability. While the process has a disadvantage of its own as well that is organic molecules are not removed while application of this process thus they can collect and form clogs on the membrane. At low conductivity the power consumption increases due to low concentration (at 400 PPM) [13].

\subsection{Photo-Catalysis}

As we have already read that the ED process has a limitation that it cannot remove organic molecules form the wastewater. So for this purpose photo-catalysis is used which uses sunlight as a source to mineralize the organic pollutants completely. A complex series of reactions are followed during the breakdown process. A catalyst like $\mathrm{TiO}_{2}$ is used for this purpose. The catalyst is activated by the UV spectrum and thus hydroxyl radicals are produced .Electronholes pair gets created when the semi-conductor is made to irradiate through energy which is equal or greater than the band-gap of the given semiconductor. The electron-hole pairs get created which can either go to recombine or else can migrate towards the surface of the semi-conductor to make reactions. If presence of any organic compound gets detected they get attacked virtually by the activated catalyst to form non-hazardous products like carbon-dioxide and water. The setup used has a special design of its own where a parabolic trough collector receives the rays to concentrate it on a receiver.

But as usual there is a limitation of every process used. Firstly an aeration tank should be provided so as to provide extra oxygen, dissolving the organic pollutants and secondly,water is made to undergo pre-filtration so as to avoid the accumulation of particles on the walls of the reactor and prevent deactivation of catalyst [14].

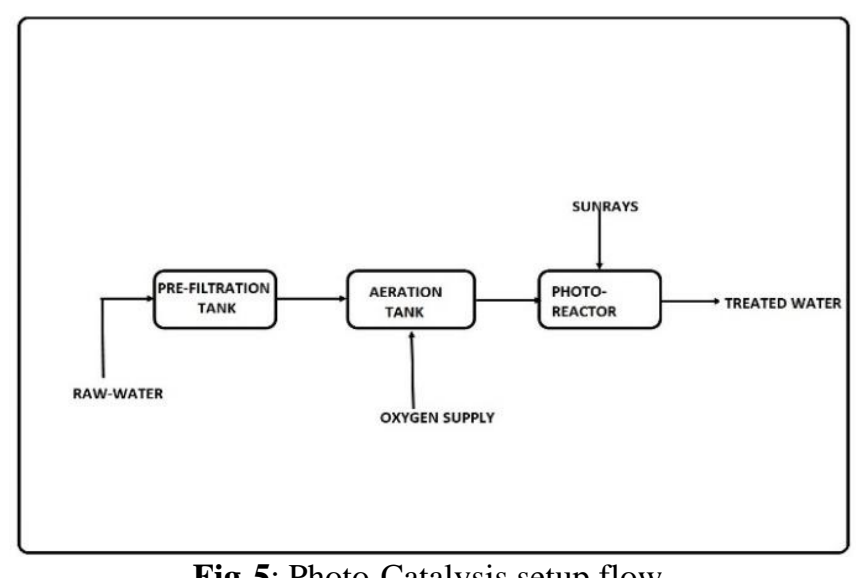

Fig-5: Photo-Catalysis setup flow

\subsection{Reverse-Osmosis}

Most of the water which is available on the earth surface is saline in nature. But due to the finite resources available the water should be desalinized and for this purpose a physical process known as reverse-osmosis (RO) is applied which finds an application in pressure to purify the saline water. The process serves the purpose of separation of permeate and the brine. When an external source of pressure is applied and the feed is made to go through a membrane of cellulose acetate, the water molecules pass through the fine pores whereas the salt particle is retained thus the process of desalinization goes on. Since the pores of the membrane are very fine the water molecules pass very slowly thus making the whole process a slow one. The power source to drive this process, PV module is chosen .But depending upon applicable areas the process of desalinization using wind power is chosen as the best renewable source of energy. In the coastal areas wind blows throughout the day either form land to sea or sea to land. This wind energy is harvested with the help of the windmills in the coastal areas and it can be used to drive the process of reverse-osmosis. The kinetic energy is derivable in the form of wind energy and can be defined by the formulae K.E. $=(1 / 2) M^{2}$, where $M$ is the mass of air and $\mathrm{V}$ is the wind speed. Now the $\mathrm{M}$, mass can be calculated as $\mathrm{M}=\mathrm{pAV}$ where $\mathrm{p}$ is the density of air and $\mathrm{A}$ is the area of rotor blade of the windmill [15]. The input in the windmill becomes the feed for the wind power system conversion which is used to drive the RO process.

The feed of the RO process is the saline water which should undergo pre-treatment so that the system's efficiency is improved and the longevity of the membrane is increased. While driving the process different pump systems arranged so as to recover the energy from the flow and this serves as a 
feedback as well. This feedback is necessary because the output from the windmill is only $30 \%$ to $35 \%$. The pretreatment of water is an additional issue to focus on [16].

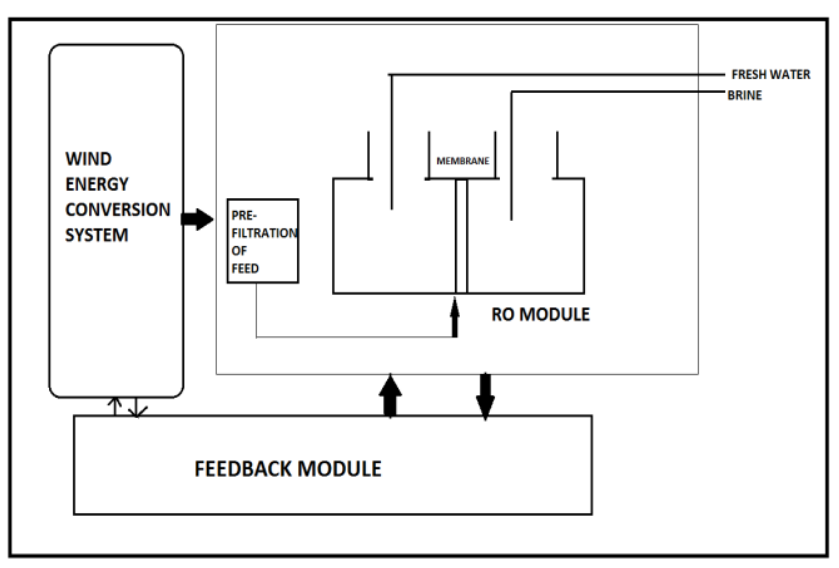

Fig -6: Reverse-Osmosis using wind-power systems

\subsection{Uv-Filters In Waste-Water Treatment}

UV disinfection is found to be an effective method to treat water in rural areas or villages. Since as discussed before, the chemicals required for treatment of water is has less abundance in rural areas but setting up a standalone system which can purify the water is always helpful in such areas. The process forms the tertiary treatment of water. UVfiltration works in such a way that when UV-rays are made to pass through the feed it kills the genetic code of the micro-organisms present but within a particular wavelength range $(254 \mathrm{~nm})$ [17]. Low pressure UV is generated when voltage is applied across the gas mixture and when made into a setup, it forms a UV lamp. A UV disinfection unit consists mainly of three components namely lamp, a powersupply and an electronic ballast. Quartz glass is used for the construction purpose as because it forms a transparent cover for passing of UV radiation, in addition preventing the water from contacting the bulb. The UV disinfection process has an acting mode which not necessary kills all the target organisms but it naturally works in a way such that it takes away the ability of the micro-organisms to replicate , prohibiting the way of its infecting the host. For the purpose of effective treatment Class A systems and Class B systems are made up. The main sources of waste-water includes those form the waste-water treatment plants, sludge from the treatment of waste-water the agricultural waste-generated which generally contains micro-organisms. However there are some disadvantages of the UV treatment used like high transmittance of feed and less turbidity of feed and with time the power of the UV lamps decrease as well [18].

\section{CONCLUSIONS}

In today's world there is an urgent need of generation of water from all the sources available as the fresh water resources available are much less. Other than just highlighting the problem there is a need to develop strategies and execute different technologies so as to support the Appreciable Technology. The waste-water generated from different sources should be properly treated. Not always the output obtained is useless. The application of different technologies mentioned above are directly or indirectly much useful, but since every system has a disadvantage of its own as well selection of proper technique to achieve maximum efficient output by treatment of waste-water is necessary. Depending on the community standards different processes are applicable. Choosing a renewable source of energy is more rational in today's world where the non-renewable resources are on the verge of being extinct. Though harnessing renewable energy and using them as a power source is somewhat a matter of strong monetary backup but it serves the prime advantage of not polluting the environment by any further means as there are no harmful outputs in addition. Since India is a developing country and as the development comes from individual conscience and ideas efforts should be brought up in coordination so as to bring a change and opt for renewable source focusing on sustainable-development

\section{REFERENCES}

[1]. N. Argaw, Renewable Energy in Water and Wastewater Treatment Applications, June 2003; Chapter 2 ,pp 3-4.

[2]. Rakesh Kumar, R. D. Singh and K. D. Sharma, Water resources of India, Current Science,10 September 2005; 89:796-797.

[3]. N. Argaw, Renewable Energy in Water and Wastewater Treatment Applications, June 2003; Chapter 22, pp 3-4.

[4]. N. Argaw, Renewable Energy in Water and Wastewater Treatment Applications, June 2003; Chapter 7, pp 48-49.

[5]. Erich Bauman, Karl Erpf, Rural Water Supply Technology Options, Skat Foundations, September 2005.

[6]. N. Argaw, Renewable Energy in Water and Wastewater Treatment Applications, June 2003; Chapter 5:31-33.

[7]. S.Vigneswaran, H.H.Ngo, C.Visvanathan, M.Sundarvadivel, Wastewater Recycle Reuse and Reclamation, Conventional Water-treatment technologies; Volume 2

[8]. J.S. Kamyotra , R.M. Bhardwaj, Municipal Wastewater Management in India, 2011 Chapter 20,pp 305.

[9]. Prof. M.S.Subramanian, Environmental chemistry and analysis, July 2014, Module 1.5, pp 7-8.

[10]. N. Argaw, Renewable Energy in Water and Wastewater Treatment Applications, June 2003; Chapter 5, pp 29.

[11]. Miro Zeman, Photovoltaic Systems, Chapter 9 , pp 9.2 .

[12]. N. Argaw, Renewable Energy in Water and Wastewater Treatment Applications, June 2003; Chapter 5, pp 29.

[13]. Prof. M.S.Subramanian, Environmental chemistry and analysis, July 2014; Module 1.5, pp 7-8.

[14]. N. Argaw, Renewable Energy in Water and Wastewater Treatment Applications, June 2003; Chapter 5, pp 33-34.

[15]. Clark C.K.Lieu, Wind-powered Reverse-osmosis 
Water Desalination for Pacific Islands and Remote Coastal Comunities, Desalination and Water Purification Research and Development Program Report No. 128,April 2009; Chapter 2, pp 7.

[16]. N. Argaw, Renewable Energy in Water and Wastewater Treatment Applications, June 2003; Chapter 5, pp 27.

[17]. Ministry Of Health, New-Zealand, UV Disinfection and Cartidge Filtration (Resources for drinking water assistance programme), December 2010; Chapter 2, pp 3.

[18]. S. Harley, B. Schuba, D. Corkal, Ultraviolet Disinfection of Private Water Supplies for Household or Agricultural Purposes, November 2008; pp 24.

\section{BIOGRAPHIES}

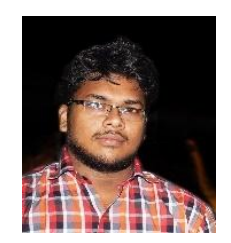

Debarghya Halder ${ }^{1}$ was born in Kolkata, India in $1995 . \mathrm{He}$ is currently pursuing his B-tech degree in Chemical Engineering from Haldia Institute of Technology, Haldia. He is currently doing his research work on Renewable energy and

Adsorption.

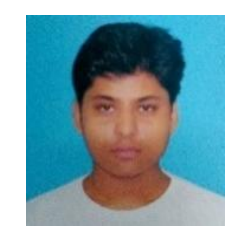

Subhojeet Mondal ${ }^{2}$ was born in Kolkata, India in 1995 . He is currently pursuing his B-Tech degree in Electrical Engineering Haldia Institute of Technology, Haldia.

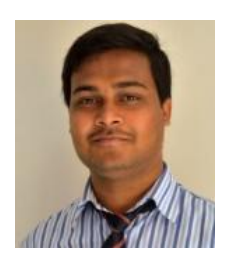

Anupam Mukherjee ${ }^{3}$ was born in Kolkata, India in 1994.He is currently pursuing his B-tech degree in Chemical Engineering from Haldia institute of Technology, Haldia. He is currently doing his research work on Adsorption, Renewable Energy, simulation and Optimization on Matlab.

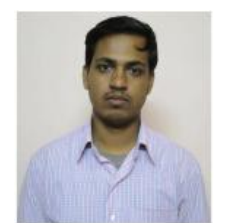

Dr. Avijit Ghosh, received his $\mathrm{PhD}$ degree from IIT Guwahati and M.Tech from Calcutta University. His research interest in the energy conversion device, graphene synthesis and its application, fuel cell. Presently, he is an assistant professor in Heritage Institute of Technology, Kolkata 